\title{
An Integrated Stress Process Theory: Viewing Intersections of Crime and Mental Illness
}

\author{
Todd William Greene ${ }^{1}$
}

\begin{abstract}
Criminal and mentally ill populations have traditionally been addressed by different systems and corrective philosophies. Recent studies, however, have identified high prevalence rates of depression and substance abuse disorders among inmates. Such comorbidity presents numerous conceptual challenges. Mental health theories are not designed to explain crime; criminology is not calibrated to explain depression. This article proposes paradigmatic modifications designed to help theory catch up with data. Criminological concepts of "criminal coping" and "deviant peers" are integrated into the Stress Process paradigm. A theory for explaining comorbidity and covariation of crime and mental illness is proposed. Social policy implications are raised. [Article copies available for a fee from The Transformative Studies Institute. E-mail address: journal@transformativestudies.org Website: http://www.transformativestudies.org (C2009 by The Transformative Studies Institute. All rights reserved.]
\end{abstract}

KEYWORDS: Theory, Mental Illness, Stress, Criminal Coping, Deviant Peers.

\section{INTRODUCTION}

Conventional perspectives dichotomize mental illness and crime into distinct and largely unrelated categories. Both "being mad" and "being bad” (Mechanic, 1999) involve social deviance, yet each is ascribed with

\footnotetext{
${ }^{1}$ Todd William Greene, Ph.D., is Assistant Professor of Sociology at Wayne State College. His previous theoretical articles have proposed models for better explaining the development, nuances, and consequences of three ideologies of individualism in the United States, and the dynamics of self-risking behavior laws. Dr. Greene is also researching how non-conventional masteries influence motivations to stay on the streets among homeless and runaway youth. Address correspondence to: Dr. William Greene, Wayne State College - Connell Hall, 1111 Main St., Wayne, NE 68787; tel: (402) 3757296; e-mail: togreen1@wsc.edu.
} 